Preprint - cite as:

Pomerantz, J., \& Stutzman, F. (2006). Collaborative Reference Work in the Blogosphere. Reference Services Review, 34(2), 200-212.

\title{
Collaborative Reference Work in the Blogosphere
}

\author{
Jeffrey Pomerantz \\ School of Information and Library Science \\ University of North Carolina at Chapel Hill \\ 100 Manning Hall, CB \#3360 \\ Chapel Hill, NC 27599-3360 \\ 919-962-8064 \\ pomerantz@unc.edu \\ Frederic Stutzman \\ ibiblio.org \\ School of Information and Library Science \\ University of North Carolina at Chapel Hill \\ 213 Manning Hall, CB \#3456 \\ Chapel Hill, NC 27599-3456 \\ 919-962-5646 \\ fred@metalab.unc.edu
}




\section{ABSTRACT}

Purpose of this paper: This paper explores the use of blogs as a platform for providing reference service, and discusses Lyceum, an open source software project from ibiblio.org, for this purpose.

Approach: The following topics are explored: the evolution of libraries' uses of blogs, the advantages of conducting the reference transaction as a collaborative effort, and the use of blogs as an environment that fosters collaboration. The argument is made that blogs may be used to good effect in reference services

Practical implications: It is argued that blogs may be used to good effect in reference services. Lyceum, an open source blogosphere application, is discussed as an environment for blog-based reference service.

What is original/value of paper: To date, blogs are not being used by a library reference services, and by few online reference service unaffiliated with libraries. This paper will be useful to libraries and other reference services interested in conducting the reference transaction as a community effort.

Keywords: Blogosphere, Blogs, Collaborative Reference, Digital Reference, Virtual Reference

Categorization: Conceptual paper 


\section{INTRODUCTION}

Blake Carver, the creator of LISnews.com, a collaborative blog "devoted to current news in the world of Library and Information Science," makes an argument for weblogs in libraries based on one of the core functions of libraries: making information accessible (Carver, 2003). Carver suggests that blogs as information sharing tools will be a fundamental element of the future of libraries. Big or small, libraries stand to benefit from the open information sharing that is facilitated by blogs.

Since 2000 or 2001, many libraries have started experimenting with blogs (Hane, 2001; Embrey, 2002). Many of these library blogs were begun essentially as electronic bulletin boards, providing a location for library-related announcements: recent acquisitions, news about or events in the library, information on reserving rooms or changes to hours. Because the purpose of these blogs is to provide a forum for announcements, rather than as a venue for discussions, many of these blogs do not allow the reader to submit comments. One example of such a blog has been maintained by the House Undergraduate Library at the authors' own institution, the University of North Carolina at Chapel Hill, since April 2003 (www.lib.unc.edu/house/ul_blog.html).

Simultaneously, many blogs were created on topics related to librarianship. These blogs are not maintained by libraries but rather by individual librarians, and serve as sources for news on topics related to librarianship (see for example, Gary Price's www.resourceshelf.com, and Blake Carver's LISnews.com), or as journals for the authors to discuss their views on issues in librarianship (see for example, Jessamyn West's librarian.net, and Lorcan Dempsey's orweblog.oclc.org).

More recently, library-related organizations have started to create blogs, both as forums for announcements, and as a venue for organizational members and any other interested users to discuss issues related to the organization. The Library and Information Technology Association (LITA) created the LITA Blog (litablog.org) in time for members to write about the 2006 ALA Annual Meeting, and LITA continues to maintain the blog for discussions of events and news of interest. The Association of College and Research Libraries (ACRL) launched the ACRLog (acrlblog.org) as a venue for discussions of issues in academic librarianship. The authorship of these blogs is often restricted - in these cases, to LITA members and an advisory board to the ACRL - but any user can comment.

Thus, even just within the relatively small universe of the library community, there are at least three different types of blogs, each with a different purpose, written for different audiences, and with different criteria for authorship and commenting. To date, however, the authors have not identified any blogs, or even literature mentioning blogs, being used by a library reference service. There is a single online reference service that makes use of blog software, which will be discussed below - but, importantly, this service is not affiliated with any library, either physical or digital. It is the authors' belief that blogs are a natural fit for use in reference services, both those affiliated with libraries and those 
affiliated with AskA services. This paper discusses the authors' vision of one possible model for the use of blogs in reference services.

\section{BLOGS}

It may be argued that for every blog author and consumer, the precise understanding of a blog's use is different. This is a testament to the personal and dynamic capacity of a blog. Searles and Sifry (2002) offer a terse, effective definition: "Blogs are journals." Doctorow et. al (2002) offer a more detailed definition: A blog is a web page that arranges discrete posts - chunks of information that may contain text, images or multimedia - in a reverse-chronological order (the most recent posts come first). Each post is uniquely identified by an anchoring link, commonly referred to as a permalink. The permalink is a persistent URL: it never changes over time, thus allowing reference to the post by anyone who wishes to hyperlink to it or cite it.

These definitions share this common ground: a blog is a web-based tool that allows an author (the blogger) the ability to post information for consumption by others. Indeed, blogs are journals - but blogs require us to reinvestigate our understanding of the term. Just as some might post their most private thoughts on blogs (a more traditional understanding of a journal), other bloggers might use their blog to create running journals of news events (media blogs), political happenings (campaign blogs), war stories (war blogs), technological achievements (tech blogs) and reference transactions (reference blogs). Indeed, the scope of blog topics reflected here vastly under-represents the potential number of blog topics. According to the Technorati "State of the Blogosphere" report, there are over 19.6 million weblogs, and total number of weblogs doubles approximately every five months (Sifry, 2005). At this rate, it seems likely that blogs will come to reflect any and all topics in which people are interested.

\section{Technical Background on Blogs}

Before exploring the potential uses of blogs, we will define the conceptual framework of a blog. At its core, a blog is a web application, managing a database which contains blog "entries." These entries are usually handled as dynamic, relational objects, from which the blog framework extracts a large part of its extensibility. The data object is related, within the blog framework, to certain core elements. These elements can serve any number of purposes - something as simple as providing a time and date stamp for a blog entry, to providing a mechanism for syndicating the blog entry to an RSS newsfeed. Of course, this list is not complete; using the relational model, blog developers have fashioned a large number of tools which allow for creative blog information sharing.

Perhaps the most widely-accepted and utilized tool inside the blogosphere is RSS. RSS, which stands for Rich Site Summary, is an XML-compliant schema for content syndication. In a nutshell, RSS offers a schema for document formatting that allows weblogs to communicate with each other. The RSS specification allows for extensible selection of elements through which blogs can automatically classify themselves. As the blog entry is related to the RSS classification data, it is formed into an XML-compliant 
document available for syndication. Formatted, this RSS document looks like little more than an awkward emulsion of code and text. When interpreted, the RSS document provides nearly limitless intelligent information-share opportunities for webloggers.

Currently, content syndication is handled by a number of methods. RSS data is often integrated into other blogs - commonly, the newsfeeds located in the sidebars of webpages are RSS syndicated streams. Content aggregators, such as NewsFire, Google Reader, AmphetaDesk, act as client-side tools that collect and display these streams for users. Stream-aggregation sites, such as Syndic8.com and Bloglines.com, offer a huge list of streams available for syndication and personalization. Meta-blogs, such as Greensboro101.com, provide publicly available aggregation and syndication of a set of blogs, generally sharing a common theme: location, genre or author affiliation are examples. Just as people have already found many different ways to extract value from RSS data, the future holds many more opportunities for how we might be able to more efficiently organize data streams with RSS.

RSS-based reference transactions grow increasingly likely as user understanding of RSS grows. Many blogging engines allow users to follow a comment thread via RSS. Imagining a reference question asked via blog, question askers would simply add the thread to their RSS readers, and be provided updates each time a response is provided to the question, or responses updated. The RSS-based reference transaction will be explored in-depth later.

\section{BLOGS AS REFERENCE ENVIRONMENTS}

As discussed above, blogs have to date been used by libraries primary as high-tech bulletin boards. We suggest, however, that blogs may be fruitfully used by libraries for other, more interactive purposes. Many library services may lend themselves to being conducted via blogs (Hane, 2001; Embrey, 2002), but we propose the use of blogs specifically for use in reference services.

Since the adoption of network technology by libraries, reference services have been provided utilizing many of new media. One of the major differences between reference services offered via different media is the degree of interactivity between the librarian and the patron, as this interactivity is dictated in part by the limitations of the media. Asynchronous media, such as email, frequently leads to reference transactions that have only two steps: the question from the patron and the response from the librarian. While this may detract from the richness of the reference transaction, the delay may allow the librarian time to conduct more in-depth research and to formulate a better response than might have been possible in a synchronous environment (Abels, 1996). Synchronous media, such as chat and instant messaging, lead to reference transactions that have pacing similar to face-to-face conversations, but this may lead to the librarian feeling rushed to provide a response quickly rather than taking the time to conduct more research and formulate a better response (Kaske and Arnold, 2002). 
The blog offers a distinctly asynchronous, conversation-based forum for reference service. Much like the more familiar tools discussion forums and bulletin boards (Jacobs, 2003), blogs provide native, web-based functionality for information transactions, while maintaining an authorial presence. This allows the blog author and information consumer the ability to create a running, public thread of malleable conversation. Each authored blog entry is anchored by a permalink (Searles and Sifry, 2002), establishing a permanent location where information consumers can refer to the conversation thread. While tools like discussion forums and bulletin boards are relatively limited in their scope of use, reference authors and consumers stand to benefit from the tools, such as Trackback and RSS, that are built and integrated for blog-enabled information sharing.

\section{Collaborative Reference Work}

Library reference has been modeled as a conversation between the librarian and the patron (Radford, 1996). In the idealized version of this conversation, the patron initiates the conversation by asking a question to the librarian. The librarian then proceeds to interview the patron to elicit more information about the patron's information need, until it is possible for the librarian to provide the patron with information and/or information sources that accurately and completely answer the patron's question.

Decades of research on reference service, however, has demonstrated that this ideal of the reference transaction is not always achieved. As Lynch (1978) found, in fewer than half of reference transactions does the librarian conduct any sort of interview, and when an interview is conducted only $10 \%$ of the time are these questions open-ended. Hernon and McClure (1986) found that only 55\% of reference transactions for quick fact and bibliographic questions conclude with an accurate and complete answer to the patron's question.

Whatever the cause of these failures of the reference transaction, we suggest that one possible means to improve reference accuracy and completeness is to expand the transaction to include more than two participants. Of course there must be an individual in the role of the patron to ask the original question that sets the conversation in motion. This is not the case for indirect reference, in which the librarian proactively responds to potential questions by creating documents, though a blog may not be the ideal environment for this type of reference work. As in indirect reference, however, a blog enables more than one librarian to participate in the reference transaction, and to respond to the patron's question. A blog is, by definition, a community exercise, encompassing a community of authors and readers. If one individual posts a question, a community of librarians - and even other patrons - may read that post and respond to it. In this way, the blogosphere may be utilized to create a "reference sphere," in which an informationseeking transaction may be conducted as community exercise.

Examples of this model of community reference work already exist. There are at least two models of community reference work: these will be called, for lack of better names, the "individual contribution" and "group authorship" models. 
One of the better-known forums for community reference work is Stumpers (domin.dom.edu/depts/gslis/stumpers/), a listserv for librarians to discuss reference questions to which they are unable to find answers. These "stumper" questions are posted to the list and hopefully (though not always) answered by other members of the list. Stumpers is an example of individual contribution reference work, in that once a question is posted, multiple individuals may respond. Like any listserv, the original post and all responses to it form a thread, and all posts in a thread may be viewed in the Stumpers archive sequentially. Each post to the list, however, remains discrete; there is no mechanism for all responses to be merged in some way. Should a question be fortunate enough to receive multiple responses, the user who wants to view all of these responses will have to view each one sequentially.

An example of the group authorship model of collaborative information service provision is Wikipedia (en.wikipedia.org). Wikipedia is of course not a reference service: it contains no question-answering functionality, either automated or human-intermediated. Wikipedia is, however, an encyclopedia, and encyclopedias are a genre of information source that is commonplace in library reference work. Wikipedia is an example of group authorship in that it is a collaborative effort: any user can edit any Wikipedia entry, and the individual contributions to an entry are subsumed into the greater whole (unless one views the entry's history). Certainly there are important distinctions between a wiki and a blog, both in terms of functionality and usage. There has also been vigorous debate about the quality of Wikipedia as an information source, and the appropriateness of using it for library work; appropriately, this debate crosses the lines of genre, from scholarly research (Viégas, Wattenberg, and Dave, 2004) to newspapers (Fasholdt, 2004) to the library literature (Ishizuka, 2004) to the blogosphere (Halavais, 2004). Nevertheless, Wikipedia demonstrates that it is possible to create an information source - and a source that at least some consider to be useful and to contain quality information - collaboratively and publicly.

\section{Blogs for Collaborative Reference}

Like Stumpers, a blog is a forum for information sharing, and like Wikipedia, over time becomes an increasingly thorough information source. A blog is a tool through which communities of information-seekers and information-providers can collaborate.

Blogs act as organizers of data; each element in a blog is a standard data object that can be referenced. Pomerantz (2003) notes that the nature of electronic media allows the entire reference transaction to be captured, verbatim, and completely unobtrusively. The reference transaction, conducted electronically, creates an artifact that may be stored until deliberately deleted. In an email-based transaction this artifact is a "thread" of email messages; in a chat-based transaction this artifact is a transcript of the entire conversation. In both cases, the artifact contains both the user's question and the librarian's response. A blog combines these features, creating a thread of an entire conversation, but a blog adds a unique feature in that it separates the question and the response (or responses): the user's question will likely be the initial blog post, and the librarians' responses will be the comments to that post. 
Pomerantz (2003) goes on to note that one important implication of the fact that electronically-conducted reference transaction may be stored is that the reference transaction, once stored, may be utilized as an information resource. The use of the reference transaction as an information resource assumes that questions repeat - that different users may submit the same or similar questions to a reference service. It is an empirical question whether this actually occurs or not, though Coffman (2001) takes it as a given. Coffman suggests that "if we could somehow access the work another librarian had done before, there would be no need to start over answering every question from scratch" (p. 152). In a blog environment, it becomes trivial to access the work that librarians have done to respond to a question, as those responses may be referenced as unique data objects.

In a blog environment, the original question persists as a unique data object, to which librarians may subsequently add comments in response. Another implication of conducting reference via electronic media is that as a reference "thread" grows, the question "accretes" responses and resources that answer or at least address it. Posts and comments, and the information resources included in or linked to from them, become annotations to the original question and other postings to which they are a response. As more and more librarians respond to the original question, a thread grows. As a thread grows, it comes to contain more and more information related to the original question, and from more and more librarians' perspectives. In this way, the thread increases in value as a response to the original question, as over time it comes to contain broader coverage of the topic at hand and a more complete response. Completeness is one of the traditional measures of the success of the reference transaction; accuracy is another (Hernon and McClure, 1986). The advantage of blogs in this respect is that they are a community exercise; if inaccurate information is posted by any one individual, there is a community of other individuals who are in a position to correct that inaccuracy. In this way, the thread increases in value, as over time it also comes to contain a more accurate response.

There are a few online communities whise primary function is to provide a forum for users to post questions and contribute answers; Ask MetaFilter (ask.metafilter.com) is one such community. While Ask MetaFilter is not a reference service, and is not affiliated with a library, it does to a certain extent fulfill some of the same functions of human-mediated. question-answering, and so provides examples of conversation-like reference transactions.

The following question was posted recently to Ask MetaFilter: "Me and the SO want to go on a week-long civil/voting rights tour of Alabama in January." The questioner goes on to request suggestions for food, lodging, and attractions. Within 24 hours, this original post had received 15 comments in response. Some of these comments are very brief, just a sentence or two, while some are several paragraphs long with highly detailed suggestions and instructions. Some of these comments make specific recommendations, while some are offers to put the questioner in touch with locals and tour guides. In short, while not all of the comments may be useful to the questioner, there is a wide enough 
range of comments that some are likely to be. Further, the questioner's Ask MetaFilter profile contains a link to her blog, so it is possible that after her trip to Alabama, she may write a post about it, thus providing her respondents with feedback on the usefulness of their suggestions.

The purpose of Ask MetaFilter is not to provide reference service, but rather to provide an online environment "that anyone can contribute a link or a comment to" (www.metafilter.com/about.mefi). Further, the question discussed above is perhaps not a typical reference question. This example is compelling, however, because it demonstrates that reference-like interactions occur naturally within the blogosphere, even outside of reference services. Further, it is not unusual for reference librarians to receive questions asking for recommendations on any number of topics: books, local activities, restaurants, etc. A single reference librarian, in response to this question, might have provided the questioner with a travel guide to Alabama, or a book or magazine guide to local restaurants, or might have spoken from his or her own experience. Because this question was posted to a community blog, however, many individuals were able to contribute their own experience to the conversation, thus greatly increasing the value of the reference transaction, and ultimately providing a far richer response to the question than would have been possible with a single answerer.

The downside of this example is this: Ask MetaFilter is only one of perhaps millions of blogs on the internet. The cognitive load of requiring question-answerers to visit multiple blogs to follow question threads, is not optimal. RSS allows questions askers and answerers to follow all conversation threads from a centralized location, within an RSS reader. For a blog-based reference service to be successful, ideally all possible question answerers would be able to see every question. There are two possible models for "matching" questions with answerers in asynchronous reference services: a "triager" may assign a question to an answerer, or answerers may claim their own questions (Pomerantz, 2004). In a blog reference environment, there is no mechanism for assigning questions, however, so answerers must select their own questions. However, what happens if an answerer does not check the available questions for some length of time - if she goes on vacation, for example, or if another answerer claims a question that our hypothetical answerer might have claimed, had she seen it first? RSS provides the solution to this potential problem. An answerer may subscribe to the RSS feeds of one or more reference blogospheres. Each question asked in the reference blogosphere is placed in the RSS reader of the question answerer; the answerer is then able to view conversation threads at his or her leisure. When the answerer finds a specific question thread that she wishes to follow, she simply subscribes to the RSS feed for that particular question. She is then made aware of each post on the thread, via her RSS reader. In this sense, the RSS reader acts as a thread-aware messaging client; users do not need to refresh and follow tens or hundreds or webpages a day; instead, they are kept up-to-date in an efficient and sensible format via RSS feeds.

An example of a reference blogosphere that makes use of RSS to enable answerers to follow question threads is the StoryStarters service (storystarters.iis.syr.edu), developed by the Information Institute of Syracuse (iis.syr.edu). Every question submitted to the 
StoryStarters service has an RSS feed associated with it. An expert may answer a StoryStarter question on his own blog, and as long as he uses the question's trackback URL in his blog post, that post will be indexed on the StoryStarters site (see, for example, a StoryStarter question answered by one of the present authors:

storystarters.iis.syr.edu/StoryStarters/answers.php?item=3420). StoryStarters are an example of both the individual contribution and group authorship models of reference work. On the one hand, every blog author answers StoryStarter questions on his own blog. On the other hand, multiple blog authors may answer the same question, and the StoryStarters site compiles all answers so that a user may search the answers that have been provided across the entire StoryStarters blogosphere.

\section{Issues in Using Blogs for Reference Service}

This sort of community information-provision runs counter to the tradition of library reference, which has historically been a one-to-one interaction between librarian and patron. To suggest the use of blogs for reference begs the question of whether a many-toone interaction is even a scalable method of providing reference service. As stated above, models of community reference work already exist - but it is possible Stumpers and other reference listservs are special cases. Can community reference work serve the needs of all types of patrons with all types of information needs? Or is it necessary that the community be constrained by a common interest in difficult questions or some other limiting characteristic? These are empirical questions that will be resolved in time, as blogs come to be used increasingly in reference settings.

Another way in which the use of a blog for reference service runs counter to the tradition of library reference is in the matter of credentials. A great deal has been made in the reference literature about the proper role of paraprofessionals in providing reference service (Whitson, 1995): without a Masters degree in Library Science, should paraprofessionals be allowed to provide the same level of service that professionals provide? Fundamentally, the issue of credentials reduces to the question of who should be allowed to provide reference assistance, and in a situation of differentiated service, who should be allowed to provide what sort of assistance? It is of course possible to restrict authorship on a blog, as demonstrated by the LITA Blog and the ACRLog. Thus, the question becomes, how closed or open should authorship of a reference blog? Too restricted, and there may not be enough librarians to respond to all questions posted, or the thread may not grow sufficiently to build a rich set of responses. Too open, and individuals may post responses that do not contribute positively to answering the question. If paraprofessional librarians are suspect in their ability to provide quality reference service, then surely so will be the general public, even if the members of that public are regular library users. On the other hand, blogs are fundamentally tools for community information sharing. Again, it is an empirical question as to what the appropriate level of openness or restriction is for blog reference in different environments.

Finally, yet another function of library reference that blogs may revolutionize is the function of referrals. Reference services have always received questions that are outside 
their scope of service; rather than simply turn a patron away without an answer, librarians will often refer the patron to another reference service or organization for which the question is in scope. The difference between referrals from a desk reference service and from a digital reference service is who has the responsibility for completing the referral. In desk reference, if a patron is referred from one service to another, the burden is generally on the patron to contact that other service. In digital reference, on the other hand, it is not the patron that is sent from one service to another, but the patron's question: the burden is on the service that received the question from the patron to perform the referral, and on both services to work out the details of that exchange. In a blogosphere, on the other hand, referrals may not even be necessary. A patron may post a question in a reference blog that is out of scope for that particular blog or library.

However, in a blogosphere, that post may then be automatically indexed in a meta-blog. That post may then be seen by librarians and users of other blogs for which that question is in scope. Thus, a question may be effectively referred without any effort on the part of the patron or the librarian. The StoryStarters service seems to be a model of this form of reference; it will be interesting to observe over time how questions are matched with answerers.

\section{LYCEUM}

Lyceum, a software project that enables blogospheres, presents one possible approach to meta-blogging in the reference sphere. Essentially a blog server, allowing multiple users and multiple blogs per each installation, Lyceum natively supports the meta-aggregation of blog posts in a blogosphere. Allowing the implementation of blogospheres on a local level, libraries could use Lyceum to enable blog-based conversation between bloggers (staff) and commenters (patrons).

Lyceum is an open source software project designed by ibiblio.org, and licensed under the GNU General Public License (GPL, www.gnu.org/copyleft/gpl.html). It is free to use, share, and modify, and is available at lyceum.ibiblio.org. Using the popular WordPress blogging engine at its base, Lyceum facilitates an enterprise-class, multi-user, multi-blog blogosphere. Additionally, Lyceum is a tool that allows intelligent automatic information management within blogospheres.

Perhaps the best way to explain Lyceum is to describe the functions of its components. Once each piece is described, it is fairly easy to see how the software package fits together. The component that most users will come into contact with is the web interface. The web interface serves as a "dashboard" of sorts, allowing a central management point for the users' blogs, RSS feeds and, most importantly, information on intra-blogosphere activity. The notion that a localized blogosphere is a social environment informs the user experience. While the dashboard primarily serves the user in a managment function, it also allows users a glimpse on activity in the blogosphere. Users are presented hyperlinks to other posts in the blogosphere, and they can be provided dynamically relevant information such as the "most popular" posts, and "most commented upon" postings. 
This leads us to Lyceum's second component, which is actually less a component then a methodology. As a user generates a blog inside a Lyceum blogosphere, it is registered inside the local blogosphere, and the blog is classified by its creator with a set of standardized meta-classifiers, such as title, and description . These meta-classifiers are then registered with the centralized Lyceum database, creating a searchable and browseable repository of local blogs. Other participants in the blogosphere (both local and general) become aware of the new blog via an RSS broadcast.

The Lyceum database aggregates the classification data for blogs, creating a searchable central repository for the blogosphere. This centralized system is valuable to informationseekers. In the traditional blogosphere model, actors are by default unaware of others' activity; RSS feeds serve the function of keeping actors aware of each others' activity, but this requires a deliberate subscription to the feed. With Lyceum, blogosphere actors are kept up-to-date on blog activity that occurs within their local blogosphere; this information is displayed in their dashboard as a set of recent posts. As such, this "interconnectivity" provides a substantial leap forward in both the automation and relevance of content that users see within a blogosphere.

This relevance can be demonstrated through a comparison of blogosphere models. Currently, RSS streams, the most popular means by which bloggers are made aware of others' content, are streams of data that are then "read" by an aggregator. When one subscribes to a RSS stream, one receives both relevant and irrelevant data (for example, topical and personal blog posts). Lyceum's architecture allows blogosphere participants to selectively watch relevant RSS streams within their particular blogosphere. As blog posts are classified with topical information, Lyceum will make RSS streams for these classifiers available. For example, it may be the local practice to classify science reference questions with the meta-classifier "science"; users would then be able to follow an RSS stream for the science topic, ensuring they see all science reference questions in the blogosphere. The analogy best fitting the current RSS model envisions a listserv of thousands of users, discussing a multitude of topics. The signal-to-noise ratio of such a list would make it undesirable for a subscriber to the list to read every post, and nearly impossible to extract the useful data from the list. Lyceum's model envisions this same listserv, but the posts that any one user receives are filtered for content. Lyceum's model thus embodies the diversity of a listserv but the robustness of a blog.

\section{Using Lyceum for Reference Work}

Pomerantz and others (2004) present a 5-step model of the processes involved in providing digital reference service. One of these steps is Tracking: the quantitative and qualitative monitoring of questions for trends. Another step is Resource Creation: the creation of new materials for inclusion in the collection maintained by the reference service, either directly by archiving previously-asked questions (PAQs), or indirectly through the use of tracking data to indicate areas in which collections of information resources should be developed. 
Data analysis tools built into Lyceum enable Tracking to be performed easily, and authoring tools enable Resource Creation. As posts are sent to Lyceum's database, they are classified with user-created meta-descriptors; a RSS stream is then generated for each post. Users are made aware of new postings through their Lyceum dashboard, or through their RSS reader. Users may choose to track RSS streams at any of four levels of granularity: the entire blogosphere (the installation of Lyceum and all posts generated therein), the posts to a specific blog, the comment thread of a specific post on a specific blog, or all posts within a specific topic. These data streams can then be analyzed to create popularity and activity indices, providing librarians agile views into the ongoing activity in the blogosphere. Library reference services create pathfinders, and digital reference services create FAQ lists on topics on which they receive frequent questions. This data may be captured formally, through collection of statistics and measures at the reference desk, or informally, through librarians' intuitive sense of which questions are asked frequently. Lyceum allows data to be captured quantitatively through database queries, so that it is possible to capture a much richer set of measures: not only frequently-asked questions, but frequently-used topic categories, frequently linked-to URLs, users who perform this linking, most heavily commented posts, most linked-to posts, and all of this can be further organized by time or any number of other criteria.

Since each element (posts, comments, etc.) is stored as a standard data object in Lyceum's central database, statistical analysis and data mining can be performed for all of these variables and more. In storing posts and comments, Lyceum is not significantly different from other blogosphere applications. Where Lyceum differs from other blogosphere applications is twofold: Lyceum possesses (1) content-tracking functionality that enables users to harness the connectivity inherent in blogospheres, and (2) data analysis functionality that enables users to track trends in these connections within the blogosphere. As an environment for allowing users to post questions and librarians to provide comments in response, Lyceum is equivalent to other blogosphere applications. The usefulness of Lyceum as an environment for conducting reference work comes from (1) the ability of users to easily subscribe to and track the progress of threads of interest, and (2) the ability of librarians to easily track trends in questions and responses. As mentioned above, it is an empirical question whether, as Coffman (2001) claims, reference services receive repeat questions. Using Lyceum, this question could easily be answered. Further, Coffman's suggestion that reference services should reuse previous answers could be easily realized using Lyceum. StoryStarters also compiles responses to questions, but it does so by providing links to responses on a set of blogs distributed around the web. By hosting a local blogosphere, Lyceum also enables sophisticated data analysis of questions and responses.

\section{FUTURE DIRECTIONS}

As mentioned above, blogs have started to gain use in libraries, but to date have not been implemented in library reference service. It is the authors' hope that Lyceum will be implemented in libraries and utilized by reference services, and that services will study how it is used, so that over time the pros and cons of conducting reference in a blogosphere will be explored. 
At the 2003 Virtual Reference Desk conference in San Antonio, Radford (2003) presented the methodology that was used in the analysis of the Samuel Swett Green Award (www.vrtoolkit.net/greenaward.htm), to identify exemplary virtual reference transactions. This methodology is based on conversation analysis performed on face-toface interactions, and involves identifying such elements of the interaction as: factors that facilitate or hinder the relationship between the librarian and the patron, use of language by both participants, negotiation of conversational opening and closing sequences. While conversation analysis is largely concerned with two- or few-participant interactions, it may serve as a basis for studying the interaction that takes place between many participants in a blog environment. Indeed, the authors suggest that a highly fruitful avenue for future research on blogs - whether in a reference setting or not - would be studies of the conversational interactions and community-building that takes place in and through blogs.

Future work - both research and setting of policy - will also be required to address the issues discussed above in using blogs for reference service. What is the appropriate role of paraprofessionals and non-librarians in providing reference service via blogs? How can quality be maintained in responses, to avoid the sorts of criticisms leveled at Wikipedia? Is the one-to-many interaction of blogs a scalable method of providing reference service? What best practices will emerge for using blogs for reference work? These questions may be answered as blogs are implemented in reference services - in all types of libraries, used by all types of librarians, to answer all types of questions, asked by all types of patrons. The authors agree with Hane (2001) that blogs are a natural for librarians, and would add also for libraries. The authors go one step further to claim that blogs are a natural for library reference services. While much work remains to be done, this paper has explored the potential of community reference service for providing accurate and complete answers to patrons' questions, and of the potential of blogs for providing community reference service.

\section{ACKNOWLEDGEMENTS}

Thanks to all of the bloggers in the biblioblogosphere who gave us useful feedback on early drafts of this paper.

\section{REFERENCES}

Abels, E. G. (1996), “The E-Mail Reference Interview (Electronic Mail Library Queries)", $R Q$ vol. 35 no. 3, pp. 345-58.

Carver, B. (2003), "Is It Time To Get Blogging?", Library Journal netConnect vol. 128 no. 1, pp. 30-32. http://www.libraryjournal.com/article/CA266428.

Coffman, S. (2001), "We'll Take it from Here: Developments We'd Like to See in Virtual Reference Software", Information Technology and Libraries vol. 20 no. 3, pp. 149-153. http://www.ala.org/ala/lita/litapublications/ital/2003coffman.htm. 
Doctorow, C., Dornfest, R., Johnson, J.S., Powers, S., Trott, B., and Trott, M.G. (2002), Essential Blogging, O'Reilly and Associates, Sebastopol, CA.

Embrey, T. R. (2002), "You Blog, We Blog: A Guide to How Teacher-Librarians Can Use Weblogs to Build Communication and Research Skills", Teacher Librarian vol. 30 no. 2, pp. 7-9.

Fasoldt, A. (2004, August 25). "Librarian: Don”t use Wikipedia as source”, The Syracuse Post-Standard.

Foley, M. (2002), "Instant Messaging Reference in an Academic Library: A Case Study", College and Research Libraries vol. 63 no. 1, pp. 36-45.

Francoeur, S. (2001), "An Analytical Survey of Chat Reference Services", Reference Services Review vol. 29 no. 3, pp. 189-203.

Halavais, A. (2004), “The Isuzu Experiment”, Alex Halavais: a thaumaturgical compendium. http://alex.halavais.net/?p=794.

Hane, P. J. (2001), "Blogs Are a Natural for Librarians”, NewsLink vol. 24. http://www.infotoday.com/newslink/newslink0110.htm.

Henning, J. (2003), “The Blogging Iceberg”, Perseus White Papers. http://www.perseus.com/blogsurvey/thebloggingiceberg.html.

Hernon, P., and McClure, C. R. (1986), "Unobtrusive Reference Testing: The 55 Percent Rule", Library Journal vol. 111 no. 7, pp. 37-41.

Howard, E. H., and Jankowski, T. A. (1986), "Reference Services via Electronic Mail", Bulletin of the Medical Library Association vol. 74 no. 1, pp. 41-44.

Kathy I. (2004), “The Wikipedia Wars”, School Library Journal vol. 50 no. 11, pp. 2425. http://www.schoollibraryjournal.com/article/CA475534.html

Jacobs, J. R. (2003), "Blogosphere: Exploring the New Killer App for Librarians", Documents to the People Magazine vol. 31 no. 3, pp. 6-7.

Kaske, N., and Arnold, J. (2002, 15 June), “An Unobtrusive Evaluation of Online Real Time Library Reference Services", Paper presented at the Library Research Round Table, American Library Association Annual Conference, Atlanta, GA.

http://www.lib.umd.edu/groups/digref/kaskearnoldunobtrusive.html.

Kittle, P. W. (1985), "Putting the Medical Library Online: Electronic Bulletin Boards... and Beyond", Online vol. 9 no. 3, pp. 25-30. 
Lynch, M. J. (1978), "Reference Interviews in Public Libraries", The Library Quarterly vol. 48 no. 2, pp. 119-142.

Pollack, A. (2003), “Is Saccone's Really A New Jersey Slice?”, Spicysashimi. http://spicysashimi.blogspot.com/2003_11_02_spicysashimi_archive.html.

Pomerantz, J. (2004), "Factors Influencing Digital Reference Triage: A Think-Aloud Study", The Library Quarterly vol. 74 no. 3, pp. 235-264.

Pomerantz, J. (2003), "Integrating Digital Reference Service into the Digital Library Environment" in Lankes, R. D., Nicholson, S., and Goodrum, A. (eds.), The Digital Reference Research Agenda, Association of College and Research Libraries, Chicago, pp. 23-47.

Pomerantz, J., Nicholson, S., Belanger, Y., and Lankes, R. D. (2004), “The Current State of Digital Reference: Validation of a General Digital Reference Model through a Survey of Digital Reference Services”, Information Processing and Management vol. 40 no. 2, pp. 347-363.

Radford, M. L. (1996), "Communication theory applied to the reference encounter: An analysis of critical incidents", Library Quarterly vol. 66 no. 2, pp. 123-137.

Radford, M. L. (2003), "In synch? Evaluating chat reference transcripts", Presented at the Virtual Reference Desk 5th Annual Digital Reference Conference, San Antonio, TX, November 17-18, 2003.

Searles, D., and Sifry, D. (2002), "Building with Blogs", Linux Journal vol. 107 no. 3, pp. 65-73.

Sifry, D. (2005), "State of the Blogosphere, October 2005, Part 1: Blogosphere Growth", http://www.technorati.com/weblog/2005/10/53.html.

Viégas, F. B., Wattenberg, M. and Dave, K. (2004), in Proceedings of the SIGCHI conference on Human factors in computing systems. ACM Press, New York, pp. 575582.

Whitson, W. L. (1995), "Differentiated Service: A New Reference Model", Journal of Academic Librarianship vol. 21 no. 2, pp. 103-111. 